\title{
Elastic analysis of reinforced masonry-frame structures under frequent earthquake action
}

\author{
Xiao Yuanhao, a \\ ${ }^{1}$ Hefei University of Technology \\ asrdfengjie@163.com
}

Keywords: Frame construction, reinforced masonry, frequent earthquake, elastic analysis Abstract: In the accelerated development of urbanization in China, it is urgent to improve the anti-seismic capacity of multi story buildings. From the disaster situation of the Wenchuan, Yushu caused by earthquake, the concrete frame infill wall in the stairwell is severely damaged, bringing serious damage to people's lives and property. In this paper, based on the elastic analysis and comparison of the two models of frame infilled wall model and reinforced masonry frame structure, studies the seismic capacity of reinforced masonry walls. The result shows that under multi-seismic action, compare the top displacement of reinforced masonry -frame structure and the maximum inter story drift angle, frame filled wall structure all decreased significantly, the overall seismic capacity improved significantly and enhance the safety of escape passage

\section{Introduction}

Finite element analysis software MIDAS/Gen 8.0, is the general structure analysis and optimization design software. In 1989, began research and development, in 2000, entered into the international market, in 2002, MIDAS / Gen completely in Chinese, on January 9, 2004, passed assessment appraisal by the Ministry of Construction MIDAS/Gen

Function strength of structural analysis is large, can perform linear and nonlinear static analysis, time history analysis, static elasto-plastic analysis, geometric nonlinear analysis, etc. It has a graphical editor, powerful post-processing capabilities and excellent analysis speed, also has very strong design features, applies to civil engineering, construction, special structure, combined structure and other designs.

MIDAS/Gen can quickly and easily define the elastic modulus of grouted block concrete masonry, linear expansion coefficient and other material parameters, so as to realize the structural design of the reinforced masonry shear wall and set up the plastic hinge for the reinforced masonry shear wall, carries out static elasto-plastic analysis.

MIDAS/Gen software is widely used at home and abroad to analyze large building structures, such as China's bird's Nest stadium and the water cube swimming center, Beijing TV station, Beijing International Airport and the Burj Dubai etc, fully verifies the accuracy of its analytical structure and analysis of the powerful, so this paper selects the calculation and analysis software.

\section{Research contents}

Now, the staircase of the town multiple-storey office buildings, teaching buildings and other building staircase, basically use a concrete frame structure, the wall is filled with masonry walls, while the strength of the filling wall itself is low, and cracks, damage, and even collapse occur soon under the earthquake action, affecting the use of escape and emergency rescue. In this paper, we can 
improve the stress condition of the staircase when the earthquake occurs, delay the destruction time of the staircase, strive more time for the personnel to escape, strengthen the staircase wall with reinforced masonry, and on the basis of the structural seismic response analysis theory, carried out elastic seismic analysis for reinforced masonry - frame structure system under the multipleEarthquake. The main contents are as follows:

\section{Establish finite element model}

The data of the test and theoretical analysis of the frame infilled wall and reinforced masonry structure are collected, based on the existing test results, the finite element model of the infilled frame structure and the finite element model of reinforced masonry frame structure are established.

\section{Analysis of the role of reinforced masonry wall}

Based on the two models, mode decomposition response spectrum method is used to carry out the elastic analysis under multiple earthquakes. From the natural vibration period, maximum top displacement, maximum inter story drift angle and maximum pressure ratio in column etc, carry out comparison analysis, and test whether meet the requirements of the relevant regulations, analyze the effect of reinforced masonry wall in frame structure staircase

\section{Elastic analysis of frequent earthquake}

\section{Introduction}

Numerous earthquake disasters show that the damage of the main structure of the frame structure is lighter under the action of earthquake, the damage mainly occurs in the maintenance structure, such as infill wall. In particular, the consequences of the destruction of the stairwell as an escape corridor are more serious. There are two ways to reduce the seismic damage of the stairs. One is to use the higher strength and lighter quality masonry materials, but it is limited to the current condition. The other is to strengthen the staircase stiffness, use the reinforced block masonry, strengthen the lateral deformation of the main structure of the stiffness, reduce the filling wall cracking, caving, avoid the escape channel blocked, endangering people's lives.

\section{Engineering cases}

In order to make the analysis model of the paper has some representative, the conclusion that have reference value to the actual project. The structure of the designed analysis should conform to the actual engineering situation. Therefore, this paper selected the actual project case of Jiyang County, Shandong Province, the four-story structure of an office building as an example

\section{Project Overview}

The seismic strength of this project is 6 degrees, the design earthquake grouping is the third group, the design basic acceleration value is $0.05 \mathrm{~g}$, the seismic fortification category is standard fortification class, the site type is class III, the design characteristic period is $0.65 \mathrm{~s}$, the basic wind pressure is $0.45 \mathrm{KN} / \mathrm{m}^{2}$, ground roughness is class B

The layout of the frame structure is shown in Figure 1,the total building size of the project is $50.6 \mathrm{~m} \times 16.4 \mathrm{~m}$, The frame height is $3.6 \mathrm{~m}$, the total height is $14.4 \mathrm{~m}$, the main beam section is $250 \times 650$, the secondary beam section is $250 \times 600$, the column section is 500x500.The concrete strength grade of beam, slab and column is C30,The elastic modulus is $3 \times 104 \mathrm{MPa}$, the bulk density is $25 \mathrm{kN} / \mathrm{m} 3$.The average line load of a $5.5 \mathrm{kN} / \mathrm{m}$ on the floor beam is considered in Maidas gen, and the line load is not considered on the roof beam. According to the load specifications [1],floor live 
load takes $2.0 \mathrm{kN} / \mathrm{m} 2$, the live load of not on the roof take $0.5 \mathrm{kN} / \mathrm{m} 2$, floor constant load takes $5.5 \mathrm{kN} / \mathrm{m} 2$, roof constant load takes $3.5 \mathrm{kN} / \mathrm{m} 2$.

\section{Establish finite element model}

By using the method of comparative analysis, two models are established, which can be used to compare the experimental data. Model one is framework filled the wall structure of the actual engineering, cycle reduction coefficient takes 0.7, the structural layout plan is shown in Figure 3.1, model two is the reinforced masonry -frame structure (on the basis of model one, replacing staircase masonry walls with reinforced masonry), cycle reduction coefficient takes 0.75 , the structural layout plan is shown in Figure 2.

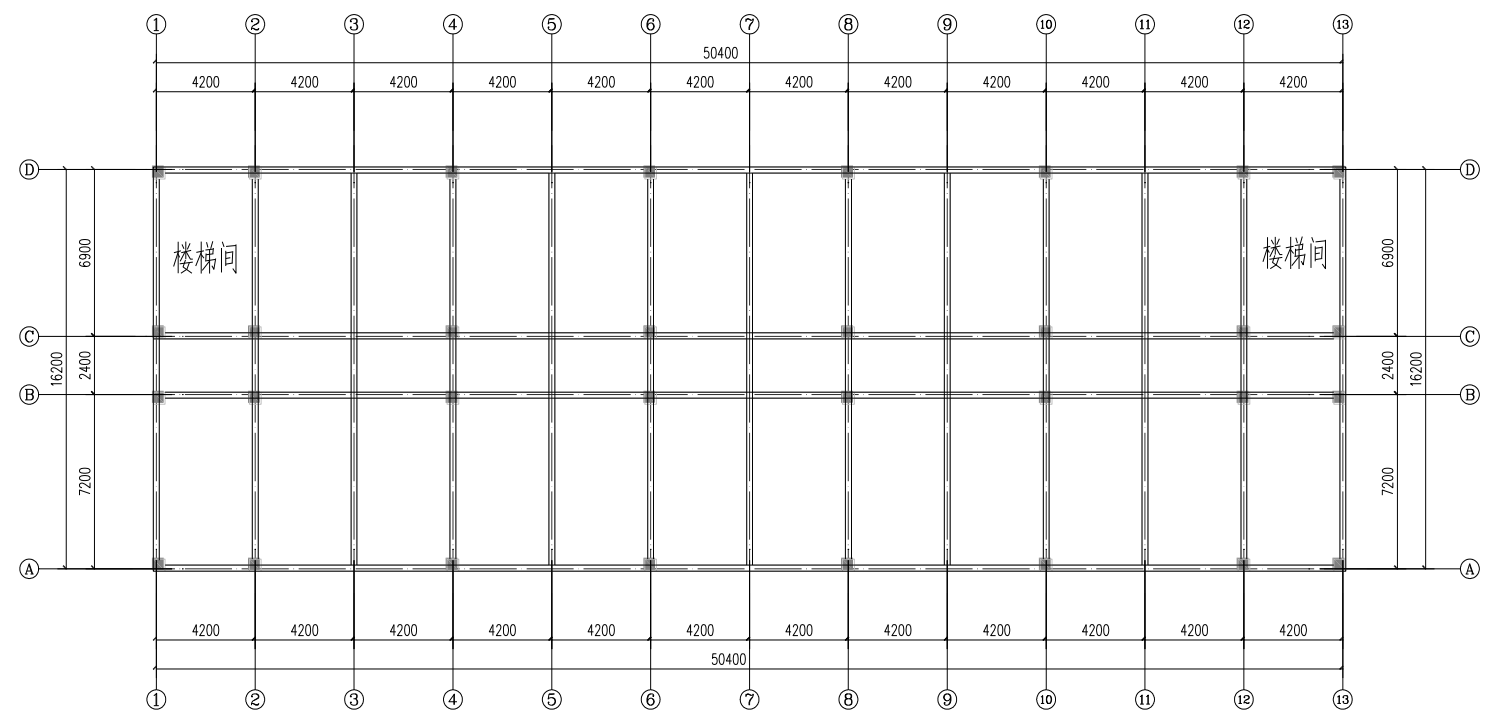

Fig. 1 The layout plan of the frame infilled wall structure

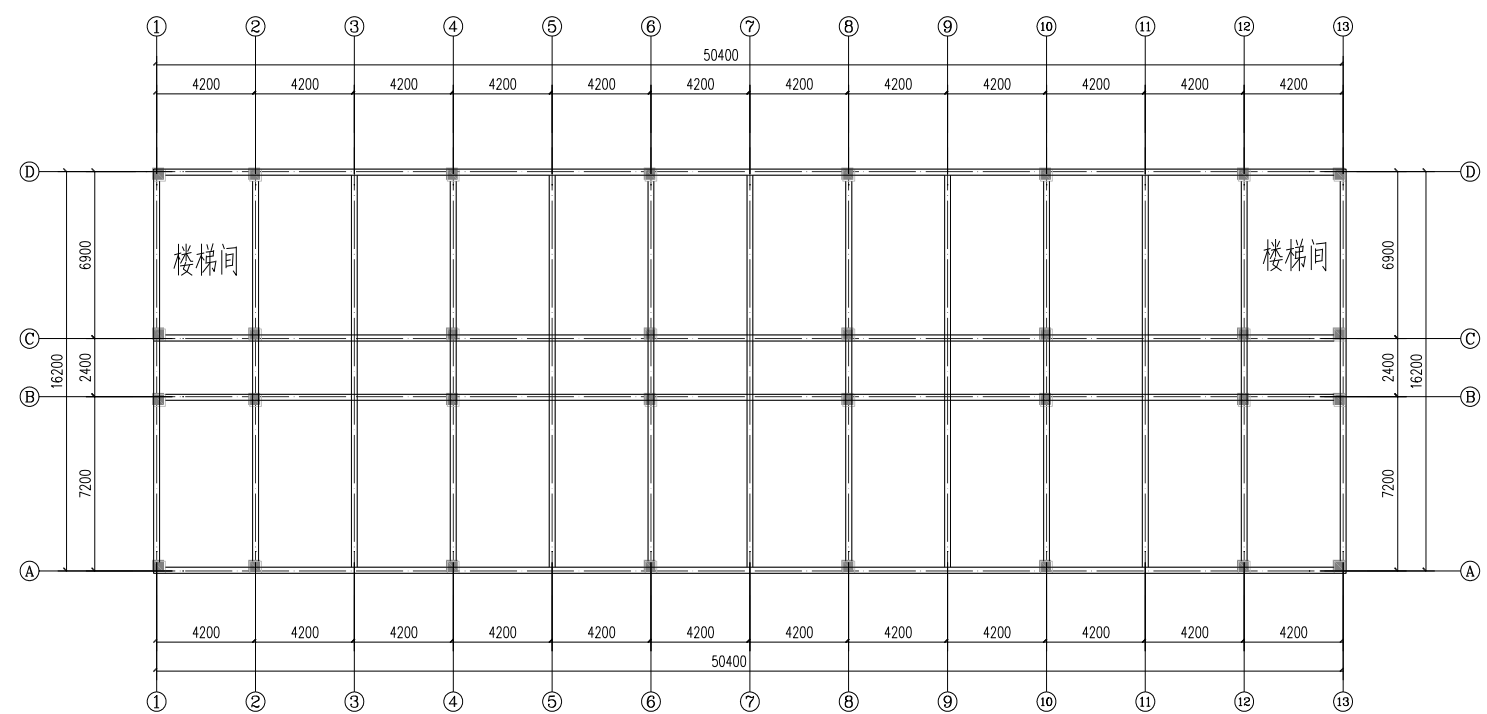

Fig.2 The layout plan of reinforced masonry-frame structure 
In the Midas gen8.0, beam and column uses beam element in the software, reinforced masonry wall adopts wall unit, the structural parameters of the block masonry are selected according to the masonry specification. Reinforced concrete masonry use small concrete hollow block size with the specification of 390mmx190mmx190mm (length $\mathrm{x}$ width $\mathrm{x}$ height), block selection selects MU20, masonry mortar selects $\mathrm{Mb} 15$, grouted concrete use $\mathrm{Cb} 30$, block hole filling rate is $46 \%$, filling rate is $100 \%$

Check the masonry specification, the design value of the compressive strength of the filling hole of masonry is calculated as follows

$f_{g}=f+0.6 \alpha f_{c}$

$\alpha=\delta \rho$

where fg-Design value of compressive strength of masonry, should not be 2 times than the design value of compressive strength of unfilled hole masonry

$\mathrm{f}-\mathrm{MPa}$ the design value of compressive strength of unfilled hole masonry, $\mathrm{f}=5.68$

$\mathrm{fc}$ - the design value of compressive strength of Axis of fill hole concrete, $\mathrm{fc}=20.1 \mathrm{MPa}$

$\alpha$ - the ratio between the area of fill hole concrete and the rough area of masonry in the block masonry, $\alpha=0.46$

$\delta$ - Void ratio of concrete block, $\delta=0.46$

$\rho$-Filling hole rate of concrete block masonry is the ratio of the section area of fill hole concrete and section area of the hole, $\rho$ should more than or equal to $33 \%, \rho=1$ 。

So $\mathrm{fg}=5.68+0.6 \times 0.46 \times 20.1=11.23 \mathrm{MPa}<2 \mathrm{f}=2 \times 5.68=11.36 \mathrm{MPa}$

In the literature [2], analyzed the grouted masonry wall as equal strength concrete wall, the experimental results are basically in good agreement with the results of finite element analysis, so in this paper, the equal strength concrete wall is used to analyze

In the Midas gen material, input the elastic modulus, severe, linear expansion coefficient and Poisson's ratio of reinforced masonry, where check the masonry specification, linear expansion coefficient is $1.0 \times 10-5 /{ }^{\circ} \mathrm{C}$, Poisson's ratio is 0.2 . Filling hole grouted masonry Has obvious anisotropy, horizontal elastic modulus is about 0.6 0.7times [3] of vertical elastic modulus, take 0.65. Equivalent elastic modulus is calculated as follows:

$$
E_{e q}={\sqrt{E_{x} E}}_{y}=\sqrt{0.65} E=15392 M P a
$$

where, $\mathrm{E}$ is the elastic modulus of concrete block, masonry specification $\mathrm{E}=1700 \mathrm{fg}=19091 \mathrm{MPa}$. Concrete density is $25 \mathrm{kN} / \mathrm{m}^{3}$, hollow block density is $11.8 \mathrm{kN} / \mathrm{m}^{3}$, so reinforced masonry density $\gamma$ is $\gamma=0.46 \times 25+(1-0.46) \times 11.8=17.87 \mathrm{kN} / \mathrm{m}^{3}$

\section{Analysis results of structural elastic static}

\section{Effective mass coefficient}

The effective mass coefficient is also called the modal mass participation coefficient, used to determine whether or not the number of participating modes. The ratio of the sum of the effective mass of each mode to the total mass is the modal mass participation coefficient.

In China, "Code for seismic design of buildings" [4](GB50011-2010, Hereinafter referred to as "anti-compliance"), in the 5.2.2 clause description, specify that the number of vibration mode can generally take modal mass participation which reach $90 \%$ of the total mass that required modals. If all models are considered in the model calculations, modal mass participation coefficient should be 
100\%.In this paper, the number of the calculation modals is 12 in the two models, the effective mass coefficient is shown in Table 1 below, it can be seen from Table 2 that the model mass participation coefficients of the two models both meet the specification requirements

Table1 Effective mass coefficient

\begin{tabular}{cccc}
\hline Modal mass participation coefficient & $\begin{array}{c}\text { Direction X } \\
\text { translation }\end{array}$ & $\begin{array}{c}\text { Direction Y } \\
\text { translation }\end{array}$ & $\begin{array}{c}\text { Direction Z } \\
\text { reverse }\end{array}$ \\
\hline Frame filled wall structure & $95.29 \%$ & $98.52 \%$ & $95.54 \%$ \\
Reinforced masonry-frame structure & $99.53 \%$ & $98.72 \%$ & $96.56 \%$ \\
\hline
\end{tabular}

\section{Auto-oscillation period, modal shape}

The disaster after Wenchuan, Yushu earthquake show that torsional stiffness of the structure is too weak that easily suffer much more damage, the ratio of the structure of the first torsional auto-oscillation period to seismic direction the first translational auto-oscillation period, the torsion effect of the structure is obviously affected, When the ratio is close to 1 , the structural torsion is more serious. The smaller the torsion cycle, the greater the torsional stiffness, in order to improve the torsional stiffness, it is necessary to limit the torsion cycle that cannot be too long. In the "anti-compliance", clause regulated: special irregular buildings shall be specially studied and demonstrated, with special measures to be adopted. Clause description that in Table 1, the weakness of the torsional stiffness is that the torsion period ratio is greater than 0.9 , the torsion period ratio of hybrid structure is greater than 0.85 . The purpose of the torsional period ratio of controlling structure is to control the torsional stiffness that is not too weak, so as to reduce the torsional effect

Auto-oscillation period which was obtained from the two models is shown in table 2, as can be seen from table 2, auto-oscillation period of model two is less than that of model one

Table 2 Auto-oscillation period

\begin{tabular}{cccc}
\hline Auto-oscillation period & $\mathrm{T}_{1}$ & $\mathrm{~T}_{2}$ & $\mathrm{~T}_{3}$ \\
\hline Frame filled wall & 0.9532 (direction $\mathrm{Y}$ & 0.9312 (direction $\mathrm{X}$ & 0.8032 (direction Z \\
structure & translation) & translation) & translation) \\
Reinforced masonry- & 0.5673 (direction $\mathrm{X}$ & 0.4135 (direction $\mathrm{Y}$ & 0.3012 (direction Z \\
frame structure & translation) & translation) & translation) \\
\hline
\end{tabular}

Based on the comparison of the two modes of the first three modes in the table, we can see that three cycles of reinforced masonry -frame structure is smaller compare to frame infilled wall structure period, indicated that structural modal response is relatively small, the lateral stiffness of the structure is improved. Torsion period ratio of frame filled wall structure, reinforced masonry-frame structure is 0.8426、0.5309, respectively, meet the requirements of article of the "anti-compliance". From the above analysis, the reinforced masonry- frame structure can also be 
more optimized, increase the overall torsional stiffness of the structure by increasing the stiffness of the surrounding structure, so that can reduce the torsional effect

\section{Maximum axial pressure ratio of the column}

Based on the combination of seismic effect and other load effects, the maximum axial pressure ratio of the two models is shown in Table 3

Table 3 Maximum axial pressure ratio of the column

\begin{tabular}{ccc}
\hline Structure & $\begin{array}{c}\text { Frame filled wall } \\
\text { structure }\end{array}$ & $\begin{array}{c}\text { Reinforced masonry-frame } \\
\text { structure }\end{array}$ \\
\hline $\begin{array}{c}\text { Maximum axial } \\
\text { Pressure ratio }\end{array}$ & 0.79 & 0.71 \\
\hline
\end{tabular}

As can be seen from the table, reinforced masonry -frame structure can reduce the axial compression ratio, which can reduce the section size of column. "Code for seismic design of buildings"[4] (GB50011-2010 ) 6.3.6 clause "Code for design of concrete structures"[5] (GB50010-2010) 11.4.16, the limits of axial compression ratio of columns are specified, limiting the axial compression ratio is mainly to control the ductility of the column, the greater the axial compression ratio, the worse the ductility of the column, under the action of earthquake, the damage of column is brittle.

\section{Structural displacement}

Elastic inter story drift angle is that the ratio between the maximum displacement and the height of the storey is calculated according to the elastic method that limit the horizontal displacement of the structure under normal service conditions, ensure that should have the stiffness of high-rise structures, avoid excessive displacement and affect the bearing capacity, stability and use requirements of the structure.

Under the earthquake action of $\mathrm{X}$ and $\mathrm{Y}$, maximum inter story displacement angle and top displacement of the two models are shown in table 4 [6] and figure 3 - in figure 6.

Table 4 Structure top displacement and maximum inter story displacement angle

\begin{tabular}{ccccc}
\hline Structure types & $\begin{array}{c}\text { direction X } \\
\text { top displa } \\
\text { cement }\end{array}$ & $\begin{array}{c}\text { maximum inter } \\
\text { story displacement } \\
\text { angle }\end{array}$ & $\begin{array}{c}\text { direction } \\
\text { top displa } \\
\text { cement }\end{array}$ & $\begin{array}{c}\text { maxthquake action } \\
\text { story displacement } \\
\text { angle }\end{array}$ \\
\hline $\begin{array}{c}\text { Frame filled wall structure } \\
\text { Reinforced masonry-fra }\end{array}$ & 13.312 & $1 / 104$ & 10.623 & $1 / 1018$ \\
\multicolumn{1}{c}{ me structure } & 4.210 & $1 / 2993$ & 1.611 & $1 / 9673$ \\
\hline
\end{tabular}




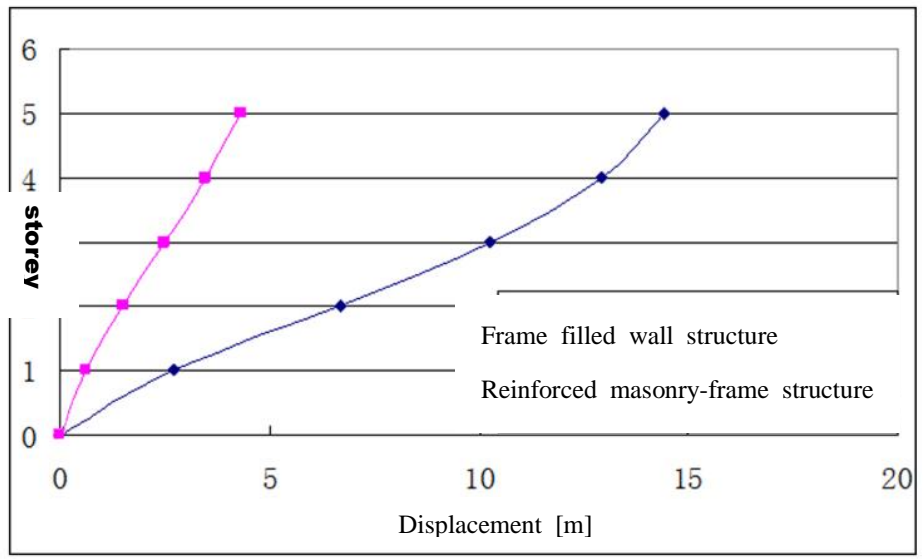

Fig 3 Direction X earthquake action storey-displacement

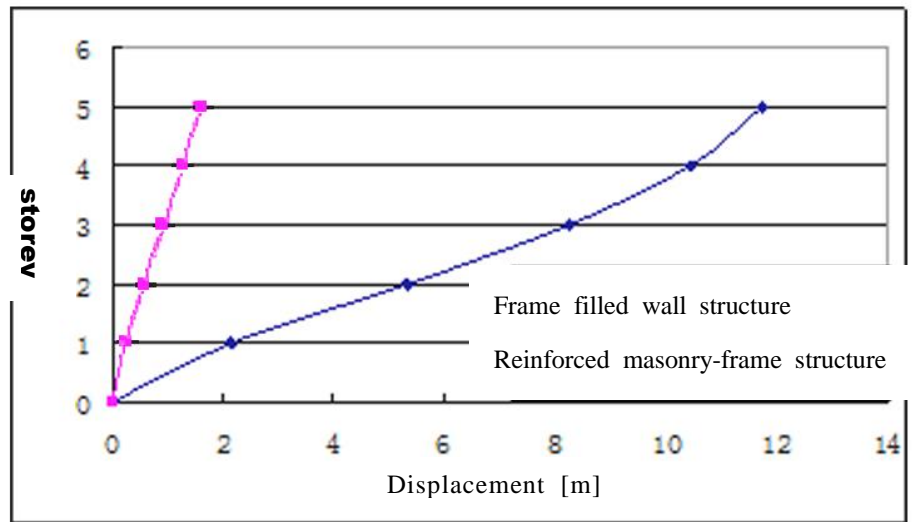

Fig. 4 Direction Y earthquake action storey-displacement

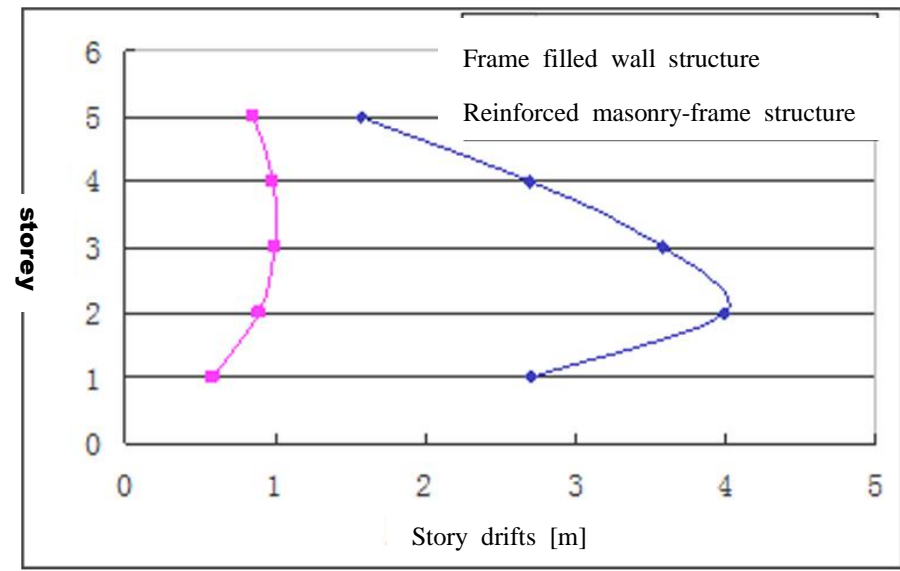

Fig.5 Direction X earthquake action storey-Story drifts 


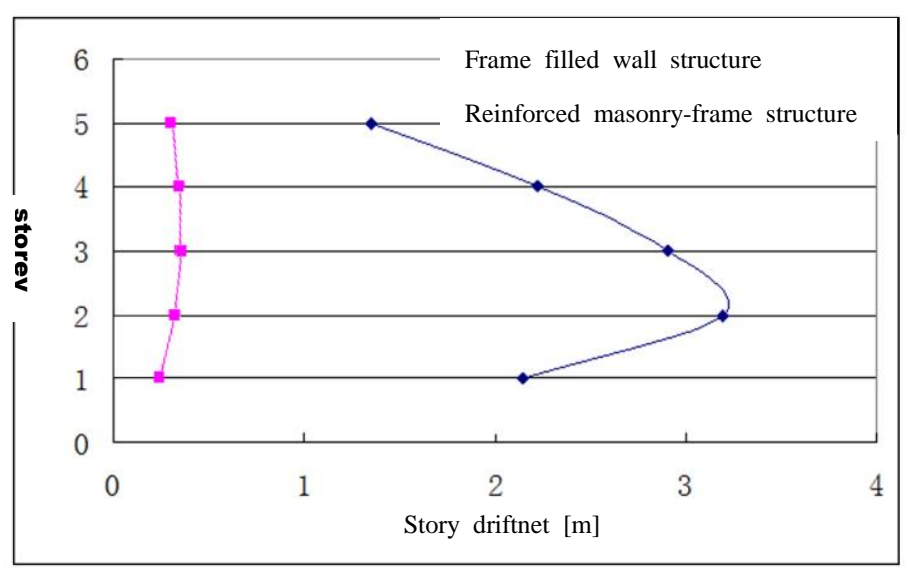

Fig.6 Direction Y earthquake action storey-Story drift

"Seismic code" set than the maximum elastic displacement angle of the frame structure is $1 / 550$, the maximum elastic displacement angle of frame shear wall structure is $1 / 800$, "Code for design of masonry structures" shows that, under earthquake action, the limited value of the maximum elastic inter story drift angle in reinforced masonry shear wall structure is $1 / 1000$, as shown in table 4 and figure 3-6, the two models meet the specification requirements. The peak displacement and the maximum inter story displacement angle of the reinforced masonry-frame structure are much smaller than the original frame structure, indicated that under earthquake action, reinforced masonry wall enhance the staircase wall that can significantly reduce the structural displacement and the displacement angle between layers, and can effectively improve the cracking of other parts of the structure, greatly improve the safety of the stairwell as an escape passage. As can be seen from table 4 , the arrangement of the reinforced masonry wall makes the top displacement of the $\mathrm{X}$ direction and the maximum inter story displacement angle larger than the Y direction, that is to say, stiffness increasing degree in the $\mathrm{Y}$ direction is much larger than that of $\mathrm{X}$, it is shown that the arrangement direction and quantity of the reinforced masonry wall will change the distribution of the lateral stiffness of the structure, replace an important part of the structure of the filling wall with reinforced masonry that should be taken into account and while it don't blindly add walls

\section{Conclusion}

Compared with reinforced concrete shear wall, reinforced masonry shear wall can significantly reduce the amount of steel, cement and other building materials, thereby reducing the cost, while accelerate the construction speed, shorten the construction period. In this paper, the infilled wall of the frame structure staircase is replaced with the reinforced masonry wall, not only can reduce the earthquake damage of the stairs, but also improve the overall seismic performance of the structure. In this paper, based on the actual project, the results of the two models are compared and analyzed that reach the following conclusions:

Under seismic action, reinforced masonry walls of reinforced masonry -frame structure, undertaking most of the seismic shear in the staircase, so that the internal force of the frame beam and frame column around the staircase is significantly reduced, plays a protective role in the stairwell.

Under multi-seismic action, compare the top displacement of reinforced masonry -frame structure and the maximum inter story drift angle, frame filled wall structure all decreased significantly, the cracking and shedding of masonry in the frame structure can be relieved, the 
results show that the frame structure layout reinforced concrete masonry wall in the staircase can enhance the safety of escape passage. Based on the analysis of the structural displacement and the maximum story drift angle, the layout of reinforced masonry wall can directly affect the torsional effect of the structure, reasonably layout wall body in design.

The comparative analysis of the maximum axial compression ratio of the two models shows that the arrange reinforced masonry wall that can reduce the axial compression ratio so that to reduce the section size of the column.

\section{Reference}

[1] GB 50009-2012.Building structure load specification. China Construction Industry Press (2012), in press.

[2] Huang Liang. MDOF Substructure Pseudodynamic Testing and Nonlinear Seismic Response Analysis of Frame-Supported Reinforced Masonry Shear Wall. Hunan University.(2005)

[3] Drysdale R G, Khattab MM. In plane behavior of grout eonerete masonry under biaxial tension-eom Pression. ACI., 92(6):653-664.(1995)

[4] GB 50011-2010. Code for seismic design of buildings. China Construction Industry Press(2010), in press.

[5] GB 50010-2010.Code for design of concrete structures. Beijing: China Construction Industry Press (2010), in press.

[6] GB 50003-2011.Code for design of masonry structures. Beijing: China Construction Industry Press (2011), in press. 